Research Paper

\title{
DISATER MANAGEMENT IN JAPAN AND EFFECTIVE USAGE OF METEOROLOGICAL INFORMATION WITH A PROMPT REPORT OF TYPHOON HAGIBIS
}

\author{
Michihiko Tonouchi $^{1}$, Koichi Kurihara ${ }^{1}$, Hiroshi Yokoyama ${ }^{1}$
}

\section{ARTICLE HISTORY}

Received: August 5, 2019 Accepted: September 22, 2019

Publish on: October 25, 2019

\section{ABSTRACT}

Typhoon Hagibis (T1919) hit area of Japan and 100 casualties and missing people were reported. The course, intensity, land timing were correctly forecasted in numerical weather models and lots of information issued almost properly, however, one of the severest typhoons in decades brought huge damages. Even if emergency warnings and evacuation directions were issued, most people did not evacuate. Evacuation in night-time was danger and earlier evacuations in comparison with day-time that recommended. In March of 2019, the guideline for evacuation was updated and risk levels of warning were categorized from Level 1 to Level 5 .

Keywords: Typhoon Hagibis, Evacuation, Disaster Risk Reduction.

\section{Introduction}

Typhoon Hagibis (T1919) landed Japan around 7pm Japan Standard Time (JST) of $12^{\text {th }}$ of October, 2019, went across Kanto/Tohoku area and passed to Pacific sea in early morning of $13^{\text {th }}$. It brought huge damage, mainly in Kanto/Tohoku area, according to the disaster report No. 35 (issued at $11^{\text {th }}$ of November) (CAO,
2019), number of casualties were 95 (32 in Fukushima prefecture and 12 in Chiba prefecture) and 5 were still missing. The number of completely collapsed houses were 1,981 , inundation house were 27,861 (above floor level) and 32,821 (below floor level) in $12^{\text {th }}$ November 521,540 houses had electric failures at midnight, suspension of water supply were 166,149 at $12^{\text {th }}$ of October, airplane cancellations at Haneda airport were 1796 (domestic) and 337 (international) at $12^{\text {th }}$ and 813(domestic), 198 (international) at $13^{\text {th }}$. Washouts of embankment were 12 points of 7 rivers controlled by country and 129 points of 23 rivers controlled by prefectures. Damage of crops were 19.52 billion, agricultural facilities were 157.8 billion, forestry was 65.6 billion and fishery was 11.5 billion Japanese Yen (each statistical data is reported at $11^{\text {th }}$ of November from ministries).

Forecasts of numerical weather prediction models from numerical weather prediction centers, i.e. ECMWF, JMA-GSM and so on, had forecasted its course, land timing and location correctly from the beginning of the week $\left(7^{\text {th }}\right.$ of October). Japan Meteorological Agency (JMA) announced that the typhoon brought huge damage to Japan firstly 3 days at $9^{\text {th }}$ (Wednesday) and media/public continuously informed fore-

$\triangle$ Michihiko Tonouchi

Corresponding author: tono@jmbsc.or.jp

${ }^{1}$ Japan Meteorological Business Support Center, Japan 
casts/warns precisely and frequently. On $12^{\text {th }}$ (Saturday), Hagibis brought strong rain mainly in front of its trajectory and orographically at slopes faced to east and south in Kanto/Tohoku area heavy rain was recorded. At Hakono (JMA AWS station in Kanagawa prefecture) recorded $942.5 \mathrm{~mm}$ precipitation in 24 hours until 21:00 of $12^{\text {th }}$, total precipitation was $1001.5 \mathrm{~mm}$, and it exceeded 3 times of monthly precipitation in October (334.3mm) (CAO, 2019).

JMA warned dangerous weather events in 3 types of information, i.e. advisory, warning. JMA issued extreme warning for Shizuoka,
Kanagawa, Tokyo, Saitama, Yamanashi and Nagano at 15:30JST (JMA1, 2019) for Ibaragi, Tochigi, Niigata, Fukushima and Miyagi at 19:50JST of $12^{\text {th }}($ JMA2, 2019) and for Iwate at $0: 40 J S T$ of $13^{\text {th }}$. The extreme warning were issued for 13 prefectures finally. Recently, JMA shared not only meteorological but met-related analysis/forecasting data, for example, landslide index, flood risk and inundation risk shown in Fig. 1. For the typhoon Hagibis, these information were timely issued and correctly reflected actual condition well.

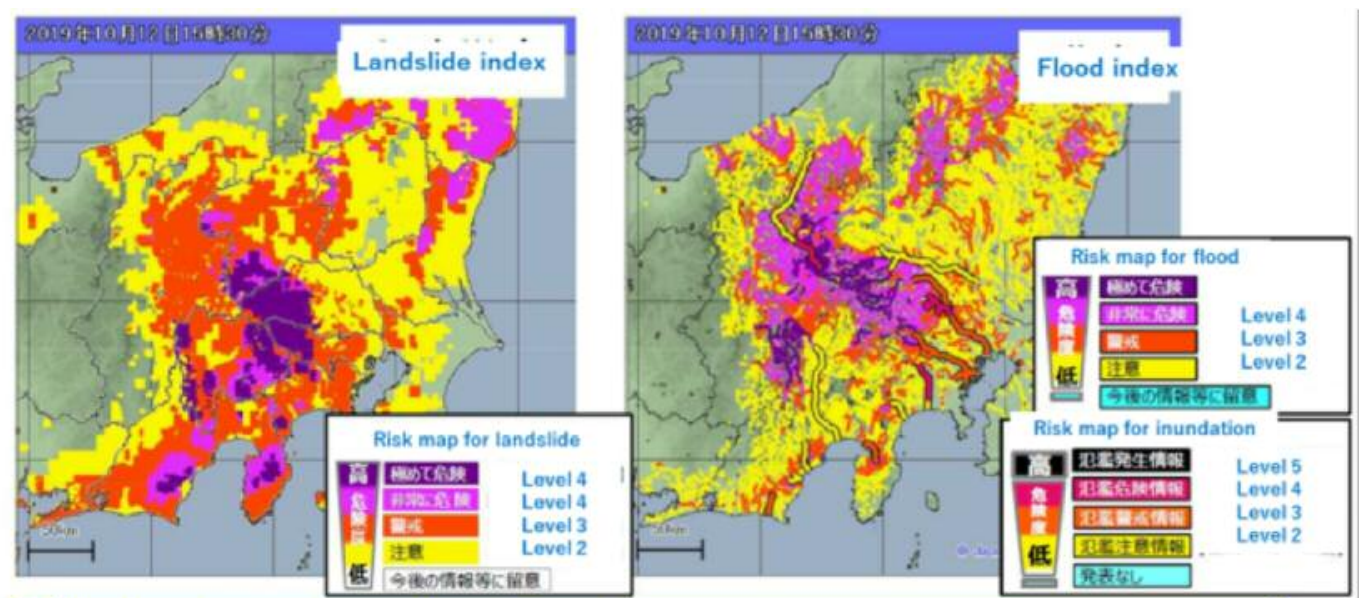

O In deepest purple area (level 5 area), because of landslides or/and floods/inundation, evacuation may be impossible/difficult. Please move to In light purple area (level 4 area), risk of landslides or/and floods/inundation became extremely higher, if possible, you're recommended evacuate soon. If you cannot, please look for safer place/zone and save your life.

Fig. 1. An example of Risk indexes for Hagibis

(captured from a JMA extreme warning report (JMA1, 2019) and translated).

JMA also managed multi language information web site for inhabitants and tourists in Japan, and information for weather warning, weather forecast, composite radar image, realtime risk map for landslide/inundation/flood, tsunami warning, earthquake information and volcano warning are shared. The web page address in Vietnamese is following (https://www.data.jma.go.jp/).

\section{Evacuation during the disaster}

For the typhoon Hagibis, weather forecasts were correct and directions for evacuation were issued from local municipal offices mostly earlier, however, 95 casualties were recorded by the typhoon.

In 2018, western Japan experienced heavy rain disaster in July and 237 casualties were recorded (JMA3, 2019). In Okayama, Mabitown located confluence area of Oda-river and Takahashi-river, one forth (1/4) of the town was inundated and the deepest depth of water exceeded to $4.8 \mathrm{~m}$ (casualties of the Kurashiki-city 
was 51). The flood occurred night-time and place/higher floor and during evacuation some some people could not evacuate higher was flown by water.

Table 1. Damage of heavy rain disaster in July 2018

\begin{tabular}{cccccccc}
\hline List & Casualties & Missing & $\begin{array}{c}\text { Heavily } \\
\text { injured }\end{array}$ & Injured & $\begin{array}{c}\text { Completely } \\
\text { collapsed }\end{array}$ & $\begin{array}{c}\text { Partly } \\
\text { collapsed }\end{array}$ & $\begin{array}{c}\text { Inundation } \\
\text { houses }\end{array}$ \\
\hline Okayama & 66 & 3 & 9 & 152 & 4,828 & 4,433 & 7,112 \\
Hiroshima & 115 & 5 & 61 & 85 & 1,150 & 5,721 & 8,957 \\
Ehime & 31 & & 33 & 2 & 625 & 3,315 & 2,679 \\
Whole Japan & 237 & 8 & 123 & 309 & 6,767 & 15,234 & 28,469 \\
\hline
\end{tabular}

In Hiroshima, lots of landslides occurred in fragile and steep slopes. This area was developed as residential area near to the city central, however, the soil contained sands and relatively fragile for rains. In this area, landslide disaster happened in early morning of $20^{\text {th }}$ August, 2014 and 74 casualties ( 73 was killed by landslides) reported. Nevertheless, landslides brought many casualties in 2018.

According to "the census for evacuation consciousness during a heavy rain event in July 2018" (Edo, 2019), 79.8 percent people (695 of totally 871 ) understood dangerous of heavy rain when they heard a comment "never experienced heavy rain in the extreme warning issued by JMA. $42.8 \%$ people collected in the context of disaster and rain, $37.7 \%$ did nothing, $22.8 \%$ confirmed their evacuation route, $19.1 \%$ checked stock of foods, $15.2 \%$ prepared evacuation goods. However, the ratio of evacuated people was $3.6 \%$ and $71.5 \%$ people judged they did not need to evacuate. The heavy rain started around noon of 6th of July and lasted until the morning of $7^{\text {th }}$ and the heaviest rain (30 to $40 \mathrm{~mm}$ per hour) were recorded at $6 \mathrm{pm}$ and $7 \mathrm{pm}$. People had felt unusual heavy rain and $35.5 \%$ people evacuated from $0 \mathrm{pm}$ to $6 \mathrm{pm}, 38.7 \%$ evacuated during from $6 \mathrm{pm}$ to midnight of $6^{\text {th }}$. On the other hand, a small town Sakamachi, $45 \%$ people (48 of totally 107) evacuated to shelters or relatives houses during the disaster.
Table 2. Evacuation activity at Hiroshima during heavy rain in 2018. (Referred from " $A$ census for evacuation consciousness during a heavy rain event in July 2018”)

\begin{tabular}{llll}
\hline List & Evacuated & $\begin{array}{l}\text { Consider } \\
\text { evacuation } \\
\text { but not } \\
\text { evacuated }\end{array}$ & $\begin{array}{l}\text { Judged } \\
\text { evacuation } \\
\text { unnecessary }\end{array}$ \\
\hline Number & 31 & 217 & 623 \\
Ratio & $3.6 \%$ & $24.9 \%$ & $71.5 \%$ \\
\hline
\end{tabular}

Mostly every year, such disasters occur and lots of papers pointed that "Normalcy Bias" brought such damages frequently. People always tend to think "someone except me encountered with an accident/disaster" and "I have never encountered with an accident/disaster for long time, at this time it would be all right for me". During the highest risk level, TV noted, "If you cannot evacuate, move to upper floor or move to opposite side from slope/river. Please choose possible way to survive", repetitively.

According to the TV interview after the disaster $\left(5: 30 \mathrm{pm}\right.$ news of NHK on $16^{\text {th }}$ October) (MLIT, 2019; Nippon, 2019), a woman lived in Fukushima (28 casualties recorded) said "after washout, the water level rose very fast, in 20 to 30 minutes up to few meters." Some old people could not evacuate to upper floor, some lived in plain houses and some people could not aware it, because river water rose at mid night. $\mathrm{Nn}$ Nagano and Tochigi, when some people tried to evacuate to evacuation facilities, their cars were flown by flooded water. In Kanagawa, after rain 
became weaker, on the way, some people tried to back to their home. The road collapsed with their car when they were passing riverside road which had become fragile. Previous disasters revealed that night time evacuation is more dangerous because people could not know information, heavy rain disturbs people to see road, river, mountain and to hear sounds from surroundings. As a consequence, an earlier evacuation in daytime is a good way to protect people from natural disasters.

\section{Frame of Disaster Risk Reduction (DRR)}

In Japan, disaster management frame is prepared in central government and preparedness frame of DRR is escalated as shown in Fig. 2.

Correspondence and activities of DRR consist from "real-time phase" and "day-to-day preparatory phase". In "a real-time phase", Local Meteorological Offices (LMOs) operate realtime dissemination network of warnings and websites dedicated to the respective local gov- ernments in order to share and exchange the information and potential risks (the number of local governments was about 1700 in July 2015). Collaboration with the prefectural governments, LMOs share real-time warning and information services on floods of specific rivers and sediment disaster and briefing/advice to prefectural governments and municipalities. LMOs implement telephone meetings/advices about countermeasures in hazardous conditions.

In "a day-to-day preparatory phase", LMOs improve operation of services through the investigation of utilizations by local governments and the public after the severe events. Clarification of warning criteria for the impact-based warnings was coordinated and the criteria was shared with local authorities and the public, through JMA Websites. In 2013, coordination of criteria for emergency warnings introduced, which was regulated in the Act to strengthen collaborations in catastrophic events.
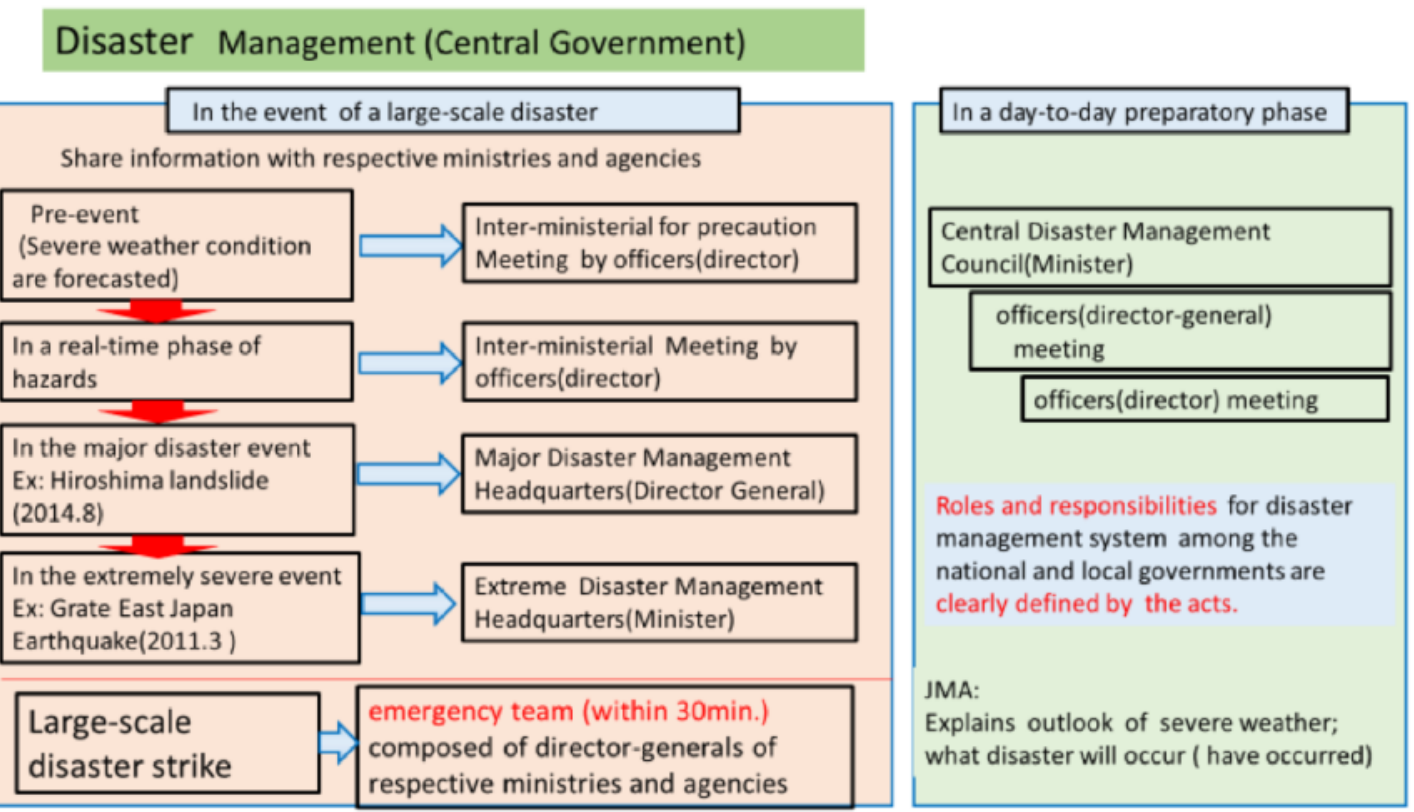

Fig. 2. Disaster management frame in central government (Hatori, 2015)

Correspondence and activities of DRR consist from "real-time phase" and "day-to-day preparatory phase". In "a real-time phase", Local Meteorological Offices (LMOs) operate realtime dissemination network of warnings and websites dedicated to the respective local governments in order to share and exchange the information and potential risks (the number of local governments was about 1700 in July 2015). Collaboration with the prefectural governments, 
LMOs share real-time warning and information services on floods of specific rivers and sediment disaster and briefing/advice to prefectural governments and municipalities. LMOs implement telephone meetings/advices about countermeasures in hazardous conditions.

In "a day-to-day preparatory phase", LMOs improve operation of services through the investigation of utilizations by local governments and the public after the severe events. Clarification of warning criteria for the impact-based warnings was coordinated and the criteria was shared with local authorities and the public, through JMA Websites. In 2013, coordination of criteria for emergency warnings introduced, which was regulated in the Act to strengthen collaborations in catastrophic events.
In prefectures and municipalities level, LMOs support or exchange meteorological information with 47 prefecture governments and around 1,700 municipalities in cities, towns, villages. Regarding DRR information, LMOs issue daily weather forecasts $24 / 7$ basis and when severe events are forecasted, bulletins for severe weather for example typhoon is successively issued. When these events start, meteorological warning is issued from each local LMO and escalated from "advisory", "warning" and then "emergency warning". Responses of municipal offices and residences are shared on JMA web site, for example as the "To-do List when Advisory, Warning or Emergency Warning is Issued" shown in Fig. 3.

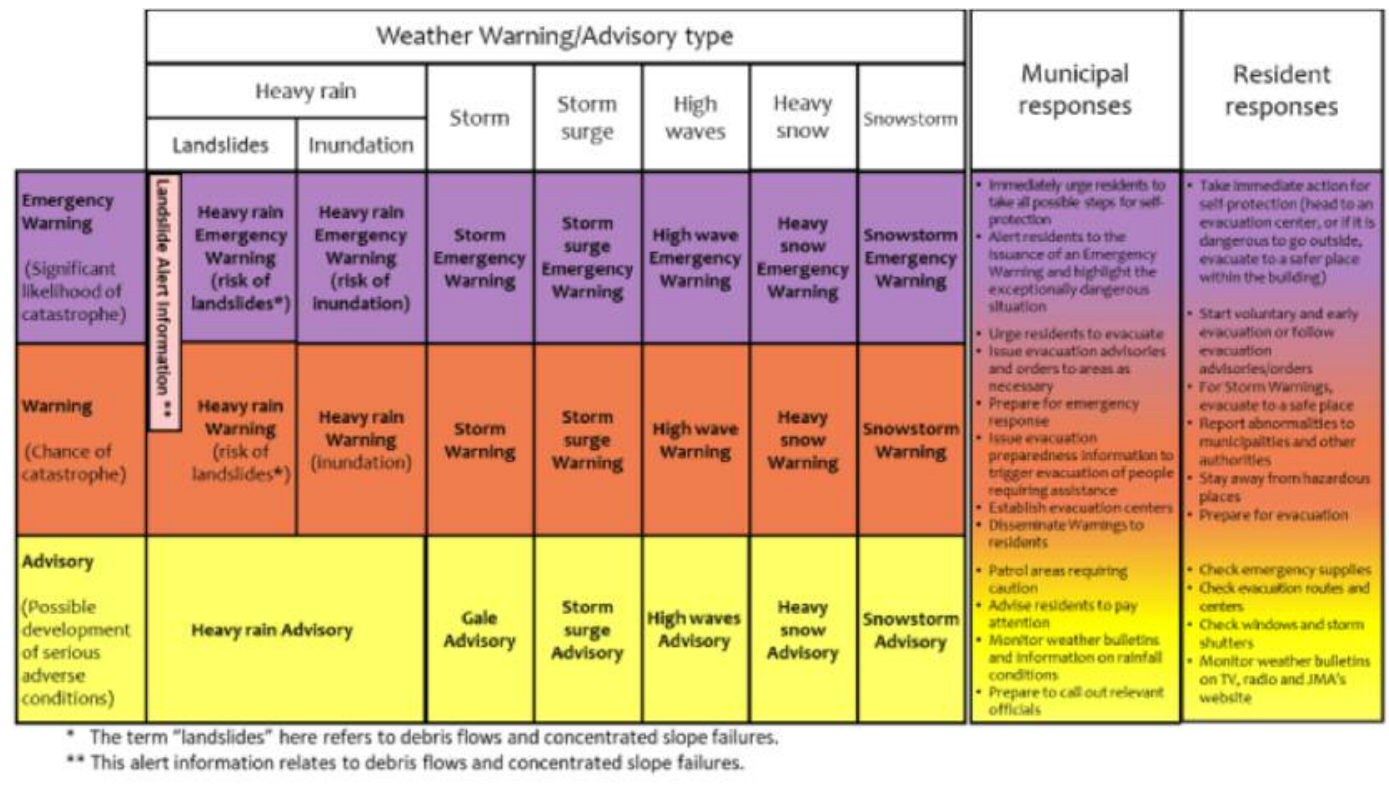

Fig. 3. The To-do List when Advisory, Warning and Emergency Warning is Issued

Weather forecasts have been improved more closely and easier to the public. For example the number of forecast/warning area was increased from prefecture level around 90 in 1953 to 1,800 blocks/municipality level in 2012. For people understanding, information includes images and illustrations help us to understand the situation objectively. On the "extreme warning for heavy rain of Hagibis", the warning included "weather chart", "typhoon trajectory", "precipitation/wind distribution map of AWSs', "composite radar image", "risk index for flood/landslide/inundation" for visual usage on medias and municipal offices. Warning mentioned the similarity of historical events and media explained risks of the event using video/photo archives of historical disasters. 

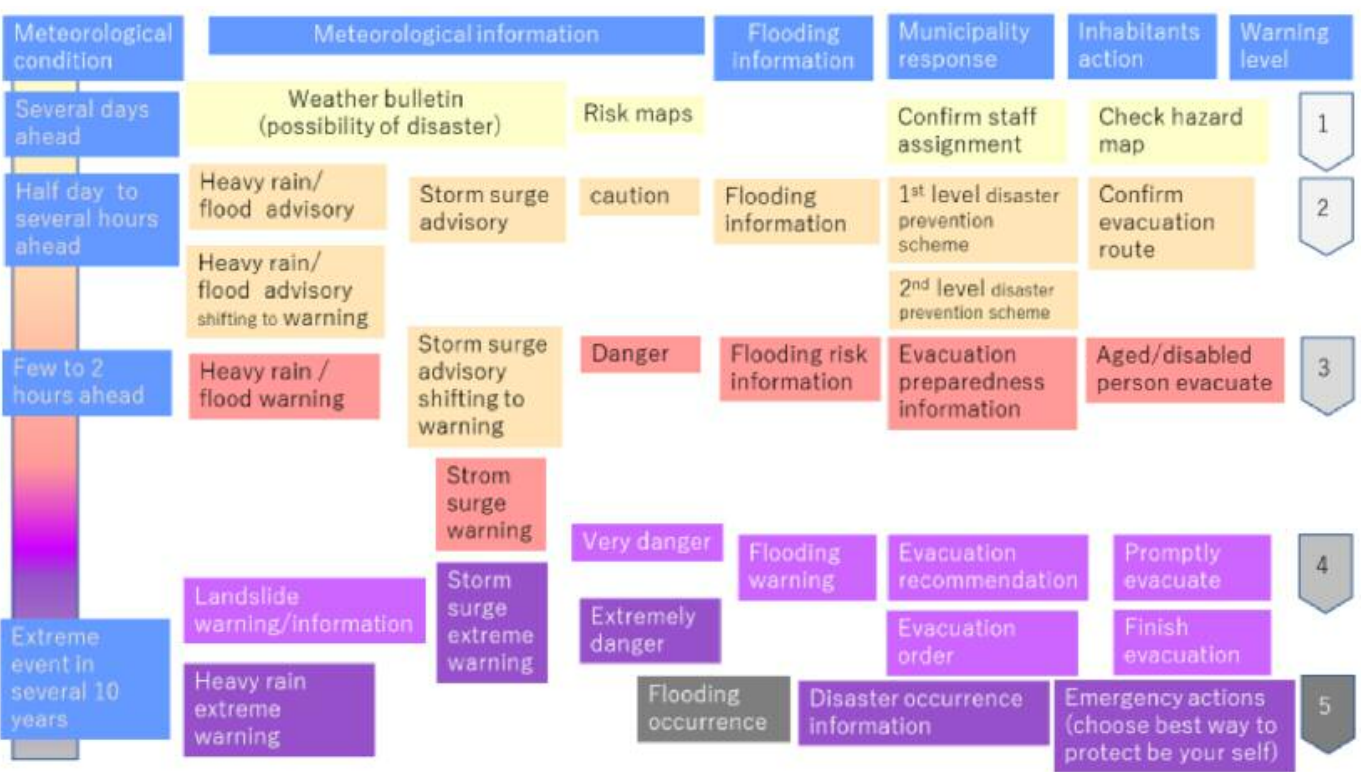

Confirm staff assignment

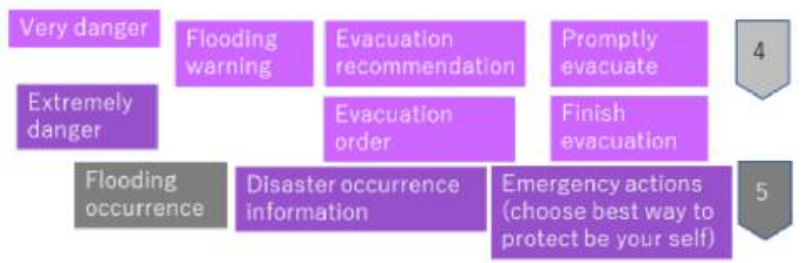

Fig. 4. Risk category of disaster information and response (Based on JMA web site: https://www.jma.go.jp/jma/)

In March of 2019, the guideline for evacuation was updated from cabinet offices, and the updated guideline, risk level of warning was categorized from Level 1 to Level 5. Meteorological condition, meteorological information, municipality response and residence response are mentioned along risk category Level 1, 2, 3, 4 and 5 shown in Fig. 4.

\section{Conclusion}

The Japan Meteorological Agency issued a warning 5 - the highest on the country's fivelevel disaster warning scale - after recording record rainfall during the 19th typhoon, internationally known as the Hagibis. This was an unprecedented level of warning in Japan for decades. The areas covered by the warning were the capital of Tokyo and six provinces including Kanagawa, Saitama, Gunma, Shizuoka, Yamanashi and Nagano. The Japan Meteorological Agency called for people living in these areas, especially those near rivers, seas and mountains, to take urgent measures to protect their lives. In the event of a move to an evacuation point where danger was encountered, it must be quickly sought to shelter in tall, well-ground houses nearby. Because natural disasters can occur at any time, Japanese have the habit of hoarding from normal living. Vietnam also needs to learn from Japan about how to respond and cope with different types of natural disasters including tropical storms.

\section{Acknowledgement}

$D R R$ frame and process are referred from JMA web site, the World Bank Disaster Risk Management Hub report and lecture materials at Takusyoku university by Hiroshi Yokoyama and JICA training course for agricultural insurance by Koichi Kurihara (not published).

\section{References}

1. CAO (The Cabinet Office of Japan), 2019. Report of damages brought by Typhoon 1919 No. 35 (viewed 14 November 2019). http://www.bousai.go.jp/

2. JMA1 (Japan Meteorological Agency), 2019. Extreme warning for typhoon 1919 for 7 prefectures, viewed 17 October 2019, http://www.jma.go.jp/jma/

3. JMA2 (Japan Meteorological Agency), 2019: Extreme warning for typhoon 1919 for 5 prefectures, viewed 17 October 2019, http://www.jma.go.jp/jma/ 
4. JMA3 (Japan Meteorological Agency), questionnaire report for evacuation during a 2019. Disaster and meteorological report" on heavy rain event in July 2018, July heavy rain in 2018 (Western Japan heavy http://www.mlit.go.jp/river/

rain), viewed 17 October 2019, 7. Nippon, H.K., 2019. NHK evening news of https://www.data.jma.go.jp/ 16th October, viewed 17 October 2019,

5. Edo, K., 2019. A census for evacuation https://www3.nhk.or.jp/news/

consciousness during a heavy rain event in July 8. Hatori, M., 2015. Modernization of mete2018, viewed 14 November 2019, orological services in Japan and lessons for dehttps://mba.pu-hiroshima.ac.jp/ veloping countries. The World Bank Disaster

6. MLIT (Ministry of Land, Infrastructure Risk Management Hub, and Transport), 2019. Investigation report for sehttps://www.gfdrr.org/sites/ curing effective evacuation from landslides, 